\title{
IMPLEMENTASI INFORMATION RETRIEVAL DALAM PEMBUATAN APLIKASI PIANO COMPOSER MENGGUNAKAN JAVA APPLET
}

\author{
Marinata Vanny Tarida Sitohang, Anton Setiawan Honggowibowo, Dwi Nugraheny \\ Teknik Informatika STTA Yogyakarta \\ informatika@stta.ac.id
}

\begin{abstract}
Music is an integral part in human lufe nowadays. A musical instrument that is being used commonly by the musician is piano. The piano is used because of its widest range of musical notes compared to other musical instruments, and those enable musician to compose musical notes with a piano. In general, there is one obstacle that prevents musician to have a piano, and that is the expensive price of a piano.

On this Final Assignment, there is a java based piano composer applet that runs on the web platform to provide an easier way to play a piano and music composition online. With this application, the user only need to compose the musical score, then the application itself will process it into a MIDI formatted file.

Based on the survey held with some musicians, can be concluded that the piano composer application can be used by the user to play piano and to compose musical notes very well.
\end{abstract}

\section{Keywords: Information Retrieval, Piano Composer}

\section{PENDAHULUAN}

Kehidupan manusia di dunia ini tidak akan lepas dari sebuah hiburan, baik dari kalangan anak-anak, remaja dan dewasa. Musik merupakan sesuatu bagian dari hiburan. Ada berbagai jenis aliran musik dan juga alat untuk memainkan musik tersebut. Aliran musikmusik tersebut seperti musik klasik, jazz, pop, rock dan lain lain.

Seiring berjalannya waktu, perkembangan musik didunia ini semakin berkembang pesat, serta berpengaruh pada banyaknya orang yang ingin belajar untuk memainkan alat musik. Hal ini dapat dilihat dari semakin banyaknya jumlah musisi, jumlah sekolah-sekolah musik serta guru les privat. Jika diamati, salah satu alat musik yang paling banyak diminati adalah piano/keyboard. Hal ini terjadi dikarenakan piano menjadi salah satu kunci instrumen musik.

Piano merupakan alat musik yang sangat disenangi oleh musisi baik dari kelas bawah maupun kelas atas. Piano tersebut juga sangat penting untuk dipelajari, itu dikarenakan range nada piano paling lebar dibandingkan dengan instrument musik lain serta dapat sebagai panduan awal dalam mengkomposisi lagu atau musik. Piano juga alat musik yang sangat mahal. Untuk kalangan menengah kebawah, hal ini tidak memungkinkan pemain musik memiliki sebuah piano. Hal ini juga membuat pemain musik susah untuk bermain piano serta mengkomposisi musik yang mereka inginkan.

Oleh karena itu tugas akhir ini dibuat untuk mempermudahkan pemusik, khususnya masih pada "taraf pemula" dan juga kalangan menengah kebawah untuk dapat menggunakan piano secara online sebagai sarana untuk belajar piano tanpa harus memiliki 
sebuah piano serta dapat membuat musik sendiri dengan layanan komposer yang terdapat pada aplikasi ini.

\section{PEMBAHASAN}

Nada ialah bunyi yang teratur, artinya: mempunyai bilangan getar (frekuensi) yang tertentu. Tinggi rendahnya bunyi (suara) bergantung pada besar/kecilnya frekuensi tersebut. Dalam musik, tinggi rendah dan panjang pendeknya nada dapat ditunjukkan dengan tanda yang disebut titinada atau not. Jadi not berfungsi sebagai huruf musik. Bila orang yang membunyikan huruf-huruf musik (not) dengan mulut atau instrument, maka terdengarlah musik. Nada-nada yang telah dibuat biasanya juga disebut dengan score.

Dalam musik internasional dipergunakan 7 (tujuh) buah titinada pokok, yaitu:
C D
E $\quad \mathbf{F}$
G
A
B

serta ada 5 (lima) nada lagi yang letaknya ada diantara nada-nada tersebut, yaitu:

$$
\text { C\# D\# F\# G\# A\# }
$$

disebut juga nada kromatis.

\section{Kecepatan Lagu (Tempo)}

Dalam dunia musik kecepatan lagu disebut sebagai tempo. Secara umum ada 8 istilah tempo utama yang sering dipakai. Selebihnya merupakan pengembangan dari istilah tempo. Istilah tempo utama dapat dilihat pada tabel 1.

Tabel 1 Istilah Tempo Utama

\begin{tabular}{|c|c|c|}
\hline $\begin{array}{c}\text { Tingkat } \\
\text { Kecepatan }\end{array}$ & $\begin{array}{l}\text { Istilah } \\
\text { Tempo }\end{array}$ & $\begin{array}{c}\text { Angka } \\
\text { Metronome }\end{array}$ \\
\hline $\begin{array}{l}\text { A. Lam } \\
\text { bat Sekali }\end{array}$ & $\begin{array}{l}\text { Larg } \\
\text { Lento }\end{array}$ & $\begin{array}{l}40-60 \\
\text { permenit } \\
60-66 \\
\text { permenit }\end{array}$ \\
\hline $\begin{array}{ll}\text { B. } & \text { Lam } \\
\text { bat } & \end{array}$ & Adag & $\begin{array}{l}66-76 \\
\text { permenit }\end{array}$ \\
\hline $\begin{array}{ll}\text { C. } & \text { Seda } \\
\text { ng } & \end{array}$ & $\begin{array}{ll} & \text { Anda } \\
\text { nte } & \\
\text { - } & \text { Mode } \\
\text { rato } & \end{array}$ & $\begin{array}{l}76-108 \\
\text { permenit } \\
108-120 \\
\text { permenit }\end{array}$ \\
\hline $\begin{array}{ll}\text { D. } & \text { Cepa } \\
t\end{array}$ & $\begin{array}{l} \\
\text { go }\end{array}$ & $\begin{array}{l}120-160 \\
\text { permenit }\end{array}$ \\
\hline $\begin{array}{l}\text { E. Cepa } \\
\text { t Sekali }\end{array}$ & $\begin{array}{ll}\text { - } & \text { Viva } \\
\text { ce } & \\
\text { - } & \text { Prest } \\
\text { o } & \end{array}$ & $\begin{array}{l}160-184 \\
\text { permenit } \\
184-208 \\
\text { permenit }\end{array}$ \\
\hline
\end{tabular}




\section{Pedal Piano}

Pada sebuah piano klasik secara umum selalu dilengkapi tiga buah pedal yaitu :

1. Soft Pedal atau Sharp Pedal yaitu untuk mempertajam dan memperpendek suara.

2. Sostenuto Pedal atau Pianissimo Pedal digunakan untuk menahan sebuah nada/not secara spesifik, dan kemudian dapat memainkan not lain tanpa terpengaruh dengan not yang ditahan sebelumnya.

3. Sustain Pedal fungsinya untuk melanjutkan terus suara piano tersebut.

Pada tugas akhir ini, pembuatan aplikasi piano composer hanya menggunakan pedal sustain. Ini dikarenakan seorang pianis lebih sering menggunakan sustain dari pada pedal yang lainnya.

\section{Information Retrieval}

Menurut Christoper D. Manning (2008) Information Retrieval merupakan bagian dari computer science yang berhubungan dengan pengambilan informasi dari dokumen-dokumen yang didasarkan pada isi dan konteks dari dokumen-dokumen itu sendiri. Informasi atau data yang dicari dapat berupa berupa teks, image, audio, video dan lain-lain. Koleksi data teks yang dapat dijadikan sumber pencarian juga dapat berupa pesan teks, seperti e-mail, fax, dan dokumen berita, bahkan dokumen yang beredar di internet.

Di teknologi informasi terdapat istilah data retrieval, selain information retrieval. Data retrieval secara umum menentukan dokumen yang tepat dari suatu koleksi data, yang isi dokumen tersebut mengandung keyword di dalam query user, tidak akan pernah cukup untuk memenuhi kebutuhan informasi user. Berbeda dengan data retrieval, user dari sistem Information Retrieval lebih memperhatikan dalam mendapatkan (retrieve) informasi melalui subyek, daripada retrieve data berdasarkan query yang diberikan, karena user tidak mau tahu bagaimana proses yang sedang berlangsung.

\section{MIDI}

Musical Instrument Digital Interface (MIDI) adalah standard perangkat keras dan perangkat lunak internasional untuk bertukar data seperti kode musik dan MIDI Event diantara perangkat musik elektronik dan komputer dari merek yang berbeda.

\section{PERANCANGAN SISTEM}

Diagram Alir Data merupakan suatu model logika data atau proses yang dibuat untuk menggambarkan dari mana asal data dan ke mana tujuan data yang keluar dari sistem, di mana data disimpan, proses apa yang menghasilkan data tersebut dan interaksi antara data yang tersimpan serta proses yang dikenakan pada data tersebut. Sehingga dengan DAD ini dapat diketahui di mana data disimpan dan bagaimana transformasi datanya.

\section{Diagram Konteks}

Terdapat 1 entitas, yaitu pengguna yang dapat memainkan aplikasi dan membuat komposisi musik sendiri. Hasil dari komposisi musik piano tersebut berupa sebuah file MIDI. 


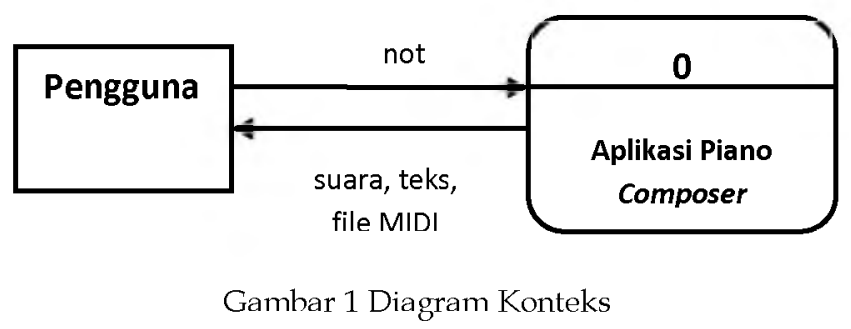

\section{DAD Level 1}

DAD level 1 seperti yang ditampilkan pada gambar 2 merupakan pengembangan dari diagram konteks, dimana pada diagram ini menjelaskan bahwa pengguna dapat mengkomposisikan score dengan menginputkan not-not kemudian score yang sudah dibuat maka disimpan sementara kedalam penyimpanan sementara kemudian score atau komposisi musik tersebut diproses kedalam bentuk file MIDI.

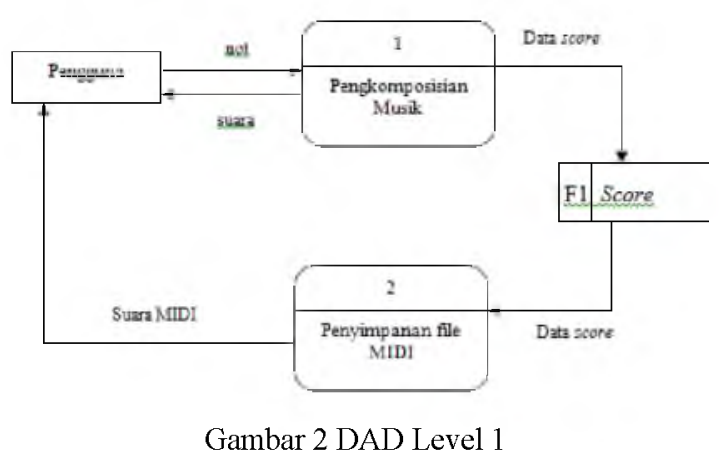

\section{Perancangan Diagram Alir Sistem}

Flowchart adalah penggambaran secara grafik dari langkah-langkah dan urut-urutan prosedur dari suatu program. Diagram tersebut dapat dilihat pada gambar 3. 


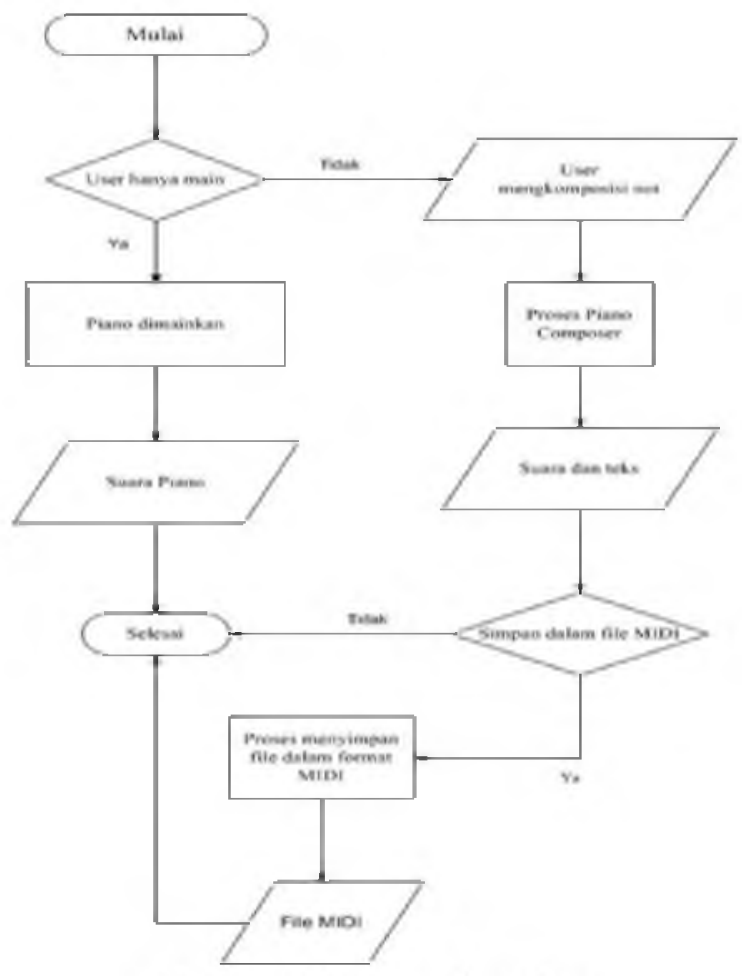

Gambar 3. Diagram alir system

Pada aplikasi Piano Composer ini rangkaian langkah-langkah pembuatannya meliputi dari awal penggunaan dari program atau dengan mengawali dengan start, kemudian menuju pada rangkaian pertanyaan untuk memilih apakah program tersebut digunakan hanya untuk sekedar bermain piano saja atau untuk mengkomposisi sebuah musik (score). Jika pilihan program tersebut ya maka program tersebut hanya digunakan untuk bermain piano saja dan program hanya dapat menghasilkan suara dari piano yang ditekan, tetapi jika pilihannya tidak maka program dapat digunakan untuk mengkomposisi musik yaitu program dapat menghasilkaan suara dan teks. Jika pengguna sudah mengkomposisi musik, maka pengguna dapat menyimpan file tersebut ke dalam bentuk file MIDI.

\section{Perancangan Antarmuka Sistem}

Perancangan antarmuka sistem mutlak diperlukan agar sistem yang dibangun dapat mudah digunakan.

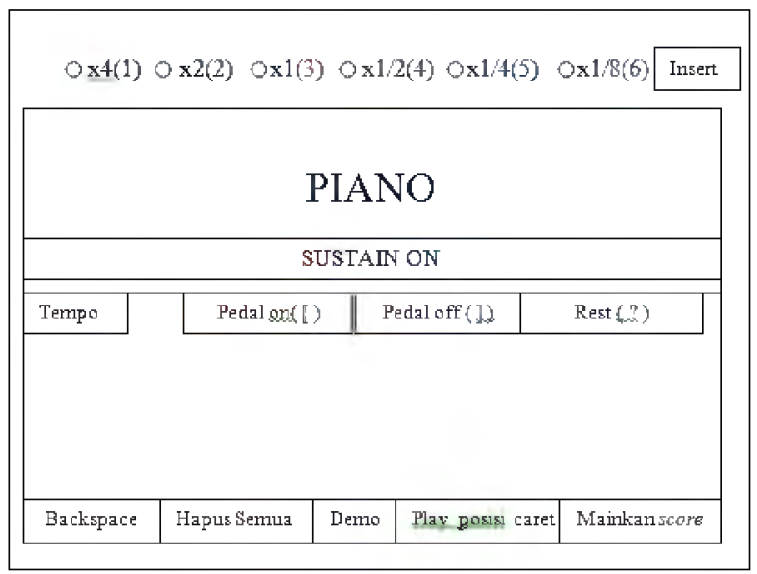

Gambar 4. Perancangan form pendaftaran 


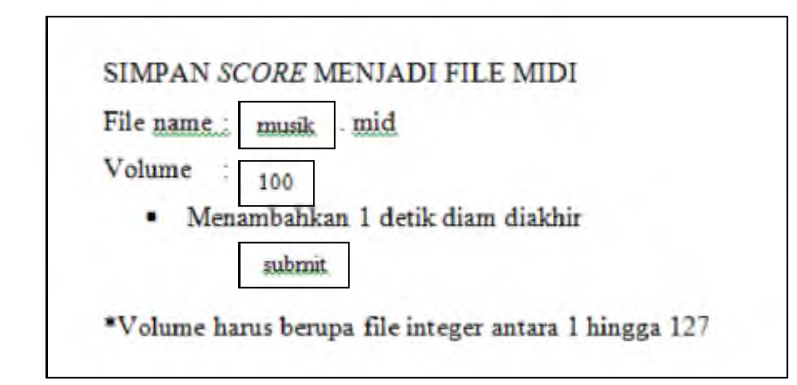

Gambar 5 Perancangan Konversi Score kedalam file MIDI

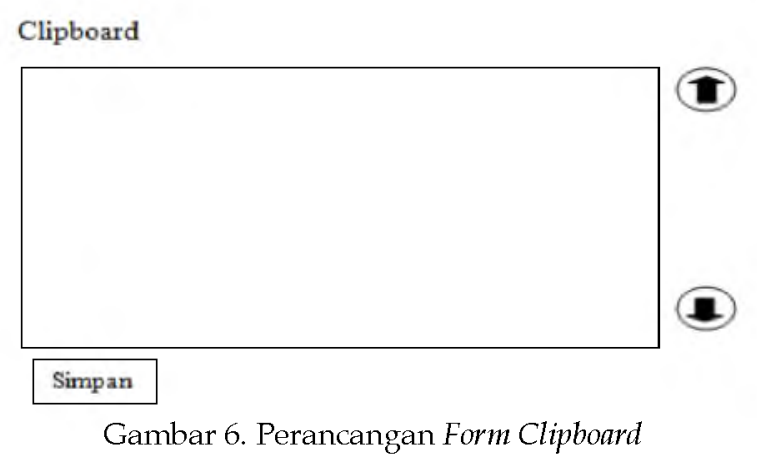

\section{Perancangan Aturan}

Pada setiap aplikasi pembuatannya pasti akan menggunakan aturan-aturan tertentu. Sama halnya dengan aplikasi implementasi information retrieval dalam aplikasi piano composer ini. Adapun aturan-aturannya terbagi dalam beberapa bagian yaitu:

1. Pembuatan score

Pada saat tuts piano ditekan akan muncul bunyi nada sesuai dengan tuts yang ditekan dan pada saat yang bersamaan dibuat pula score sesuai dengan tuts yang ditekan tersebut. Pada bagian ini nada piano yang ada menggunakan nada piano yang sebelumnya sudah disimpan dalam file .au. Sesuai dengan jumlah tuts yang ada, maka jumlah nada piano adalah 36 buah.

2. Penerapan Information Retrieval dalam pembacaan score

Pengguna membuat score dengan menekan tuts piano sehingga score yang sudah ditulis berada pada teks area kemudian pengguna mengklik tombol mainkan score maka piano akan menampilkan efek tuts yang ditekan sesuai dengan score tersebut. Pada saat yang bersamaan muncul nada sesuai dengan tuts yang ditekan. Dari bagian ini terlihat perancangan penerapan Information retrieval-nya berada saat score dibaca oleh aplikasi untuk disesuaikan dengan suara piano tersebut. Perancangan pembacaan score dibatasi pembuatan string delimiter-nya atau bisa disebut pembatas karakter dalam penulisan score. Pembatasnya itu

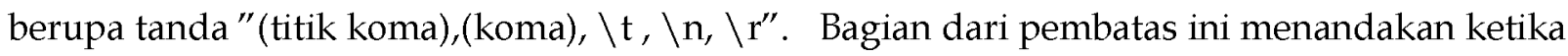
piano yang ditekan akan menghasilkan penulisan berdasarkan indeks yang ada.

3. Konversi ke dalam file MIDI

Konversi dilakukan dari score yang sudah ada kedalam bentuk file MIDI. Adapun pembuatan aturannya adalah sebagai berikut.

a. IF score kosong THEN kesalahan dalam score.

b. IF volume lebih kecil dari 1 atau lebih besar dari 127 THEN kesalahan dalam volume. 
Dari keterangan diatas dapat diketahui bahwa jika kedua baik dari salah satu peraturan tersebut tidak dipenuhi maka konversi tidak akan dilakukan dalam bentuk file MIDI. Maka dari itu kedua peraturan tersebut harus terpenuhi agar proses konversi dapat dilakukan.

4. Memainkan nada

Nada yang dimainkan sesuai dengan indeks yang dimiliki oleh tuts yang ditekan. Sehingga ketika nada score tersebut dimainkan, maka akan ada keselarasan baik dengan tempo yang sudah dipilih, ketukan serta tanda lain yang ada pada aplikasi ini.

\section{Hasil Pengujian}

Hasil pengujian merupakan bagian yang diperlukan dalam analisis terhadap sistem. Pengujian ini telah dilakukan terhadap pengguna yang dapat bermain musik khususnya bagi pengguna yang sedang tertarik dengan piano dan juga pianis. Dari seluruh data yang terkumpul terhadap aplikasi piano composer ini, diperoleh grafik tingkat kemudahan penggunaan sistem berdasarkan jajak pendapat yang diisi oleh pengguna sistem.

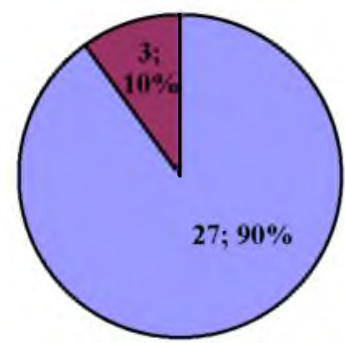

口Mudah digunakan

Tidak Mudah

Digunakan

Gambar 7. Grafik tingkat kemudahan penggunaan sistem

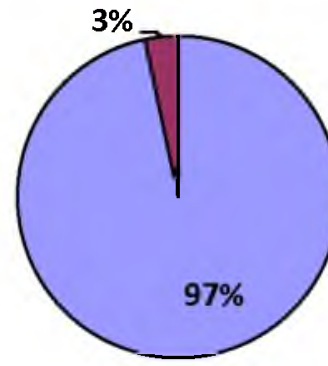

口Sesuai

- Tidak Sesuai

Gambar 8. Grafik Tingkat kesesuaian nada piano composer dengan piano umum berdasarkan frekuensi

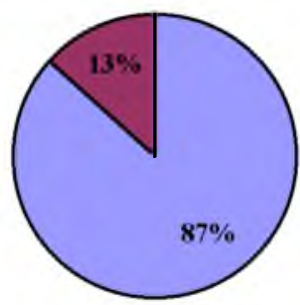

Mudah dikenal

Tidak mudah dikenal

Gambar 9. Grafik tingkat kemudahan dalam mengenal nada-nada. 


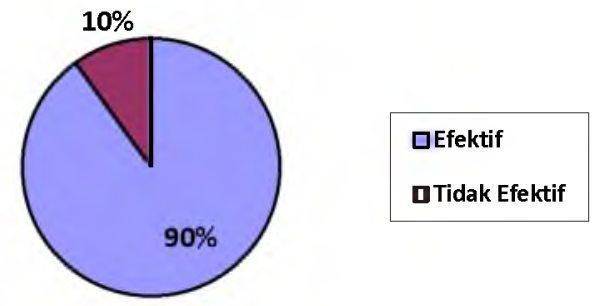

Gambar 10. Tingkat keefektifan aplikasi dalam belajar piano
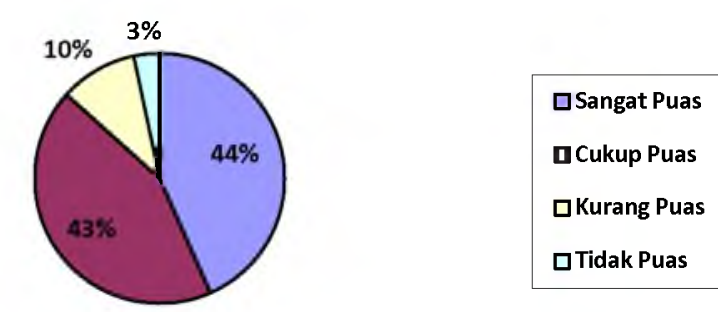

Gambar 11. Tingkat Kepuasan Pengguna Sistem

\section{KESIMPULAN}

Berdasarkan hasil analisa terhadap Implementasi Information Retrieval dalam Pembuatan Aplikasi Piano Composer Menggunakan Java Applet dapat diambil beberapa kesimpulan yaitu:

1. Aplikasi Piano composer yang dibuat menggunakan metode Information Retrieval ini dapat diakses dengan media online sehingga aplikasi ini dapat diakses darimana saja dan kapan saja.

2. Aplikasi Piano Composer dibuat dengan bahasa pemrograman Java Applet dapat membantu pemain pemula serta pemusik dalam bermain piano dan mengkomposisikan musik.

\section{Referensi}

[1] Ribeiro-Neto, Berthier, Modern Information Retrieval. New York, ACM Press, 2000.

[2] Bunyamin, Hendra., Puspa Negara, Chathalea, Aplikasi Information Retrieval (IR) CATA Dengan Metode Generalized Vector Space Model, Jurnal Informatika, Vol.4, No.1, pp. 29 38,2008

[3] Manning, Raghavan, Schutze, Introduction to Information Retrieval, Cambridge, 2008.

[4] Kusuma, Wahyu, Analisis Similaritas Melodi Menggunakan The Earth Mover's Distance. Jurnal Informatika Komputer, Vol.14, No.2, 2009.

[5] Indrajani, Martin, Pemrograman Berbasis Objek dengan Bahasa Java, PT Elex Media Komputindo, Jakarta, 2007.

[6] Hall, M., Brown, L., Core Web Programing. USA, TheSunMicrosystemPress, 2001.

[7] Al-Bahra, Ladjamudin, Analisis dan Desain Sistem Informasi, Grahallmu, Yogyakarta, 2005. 
[8] Nugroho, Bunafit, Database Relational dengan MySQL, Andi Offset, Yogyakarta, 2005.

[9] Hermawan, Benny, Menguasai Java 2 \& Object Oriented Programming, Andi Offset, Yogyakarta, 2004.

[10] Hartati, G. Sri, Pemrograman GUI Swing Java dengan NetBeans 5, Andi Offset, Yogyakarta , 2007. 